\title{
Friction Stir Processing of A-286 Stainless Steel: Microstructural Evolution during Wear
}

\author{
O.O. Tinubu ${ }^{1}$, S. Das ${ }^{1}$, A. Dutt ${ }^{1}$, J.E. Mogonye ${ }^{1}$, V. Ageh ${ }^{1}$, R. Xu ${ }^{2}$, J. Forsdike ${ }^{2}$, R.S. \\ Mishra $^{1}$, T. W. Scharf ${ }^{1, *}$ \\ ${ }^{1}$ Department of Materials Science and Engineering, University of North Texas, Denton, \\ TX 76207, USA \\ ${ }^{2}$ Rolls-Royce Corporation, Indianapolis, IN 46241, USA
}

Abstract

The effect of friction stir processing (FSP) on mechanical and wear behavior was investigated for A-286 stainless steel, an Fe-Ni-Cr based austenitic, precipitation hardened alloy. The alloy was characterized in different processed conditions, namely as rolled (AR) + aged and FSP + aged. High frequency reciprocating sliding wear behavior and wear mechanisms were investigated at room temperature. The Vickers microhardness and wear rates were measured and compared for each processing condition. It was determined that along with increasing microhardness in the stir zone, FSP resulted in improved wear resistance. Specifically, the wear rate in the stir zone was reduced from $1 \times 10^{-6}$ to $6 \times 10^{-7} \mathrm{~mm}^{3} / \mathrm{N} \cdot \mathrm{m}$ due to FSP. Mechanistic studies were conducted to determine the effect of FSP on the microstructural evolution during wear. Scanning electron microscopy revealed increased coarse abrasion with the AR + aged alloy as compared to much finer-scale microabrasion with the FSP + aged alloy. This resulted in smaller and less abrasive wear debris, and hence lower wear rate. Furthermore, cross-sectional focused ion beam microscopy studies inside the stir zone of the FSP + aged alloy determined that increased microhardness was due to FSP-induced microscopic grain refinement resulting in HallPetch strengthening, and the corresponding wear rate decrease was due to even finer wearinduced grain refinement. With both effects combined, the level of surface fatigue wear was suppressed resulting in reduction of the wear rate. In contrast, the absence of FSP-induced grain 
refinement in the AR + aged alloy resulted in decreasing hardness and increasing wear rate. Overall, FSP of A-286 stainless steel alloy resulted in a lower wear rate suggesting it is a viable surface engineering technique to target and mitigate site-specific wear.

Keywords: Stainless steel alloys; Friction stir processing; Sliding wear; Focused ion beam (FIB) microscopy; Scanning electron microscopy (SEM)

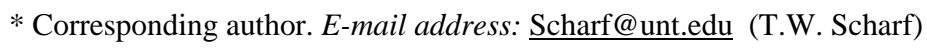

\section{Introduction}

Friction stir processing (FSP) is a relatively new solid-state processing technique that enhances the surface hardness of metallic alloys through surface microstructural modification, such as strain hardening and grain refinement [1,2]. FSP involves the use of a rotating tool with a pin and shoulder inserted into a single piece of material that travels along the desired path to cover the area of interest. The result of this process changes the alloy microstructure typically by plastic deformation, and, depending on the alloy, may also lead to recrystallization due to the exposure of heat $[1,2]$. The effect of enhanced near surface mechanical properties on the tribological behavior has been studied for many FSP metallic systems, including Al, $\mathrm{Mg}, \mathrm{Ti}, \mathrm{Cu}$, Fe, and Ni-based alloys [3-10]. In general, these studies have shown that FSP-induced hardness increase results in improved wear resistance via grain refinement and Hall-Petch strengthening.

Other methods have been used to increase the hardness and wear resistance of various alloys, in particular for steels, such as nitriding and carburizing. However, these methods do not acknowledge the material loss in steels [9] and they are very energy and often commercially costly [10]. Other drawbacks with these techniques are the entire sample must be treated as opposed to the surface only. FSP is an alternative technology to these methods since it is a sitespecific surface engineering process used to improve hardness, toughness, fatigue resistance and 
wear resistance of various steels, such as 52100 steel, 4140 steel, and AISI 420 martensitic stainless steel $[3,6,9,10]$. For carburizing, nitriding and FSP of stainless steels, the temperature at which they are exposed to are very similar, typically ranging between $720^{\circ} \mathrm{C}$ and $1050^{\circ} \mathrm{C}$ [3,6,9,11]. However, in contrast to the thermal diffusion treatments, the increase in surface hardness in the friction stirred region often reduces the extent of abrasive wear, which is expected to mitigate surface fatigue sliding wear.

In this study, FSP was applied to A-286 stainless steel alloy to determine if similar improvements in the mechanical and wear properties occurred, and to gain a better understanding of what fundamental mechanisms are responsible for such improvements. Such studies on this alloy have not been performed to date, nor have such fundamental studies of alloys in general using cross-sectional focused ion beam microscopy inside sliding wear tracks in FSP alloys. A286 stainless steel is a Fe-Ni-Cr based austenitic, precipitation hardened alloy known for its corrosion, oxidation and heat resistance. The main precipitation strengthening phase of this alloy is $\gamma^{\prime}\left[\mathrm{Ni}_{3}(\mathrm{Al}, \mathrm{Ti})\right]$. A-286 is primarily used in aerospace applications, such as gas turbine jet engines, turbine wheels and blades, frames, casings, after-burner parts and fasteners, jet engine rotors and heat resistant bolts, because it is easily heat treatable and has excellent high temperature strength and corrosion resistance up to $\sim 700^{\circ} \mathrm{C}$ [11]. However, it suffers from poor wear resistance in sliding wear contacts. Therefore, the major aim of this study is to fundamentally understand how FSP affects the wear behavior and wear mechanisms of A-286 in high frequency reciprocating sliding where such wear studies are currently unknown to the authors. High frequency reciprocating sliding was selected as the wear test method since small, multiple stroke lengths can be placed inside the relatively small friction stir zone.

\section{Experimental methods}




\subsection{Material and treatments}

A-286 is an austenitic, precipitation hardened iron-based alloy composed of nickel ( 25 wt.\%) and chromium ( 15 wt.\%) with additions of titanium ( 2 wt.\%), molybdenum ( 1.5 wt.\%), manganese ( 1.5 wt.\%), and silicon ( 0.5 wt.\%). As-rolled A-286 plates were acquired from California Metal and Supply, Inc. The as-received sheet has a thickness of $\sim 3.2 \mathrm{~mm}$. The FSP runs were conducted with a polycrystalline cubic boron nitride (PCBN) tool. The PCBN tool has a pin length of $5 \mathrm{~mm}$, a pin diameter of $7.6 \mathrm{~mm}$, and a shoulder diameter of $23.8 \mathrm{~mm}$. The PCBN tool rotation rate was $400 \mathrm{rpm}$ and tool traverse speed was $\sim 25 \mathrm{~mm} / \mathrm{min}$. Since the pin length of the PCBN tool is $5 \mathrm{~mm}$, two as-rolled A-286 plates were stacked on top of each other for FSP. Three different FSP plunge depths of 2.0, 4.0 and $4.5 \mathrm{~mm}$ were made with respect to the top surface edge. After FSP, the alloy was age hardening by heating at $720^{\circ} \mathrm{C}$ for 16 hours and air cooled to ambient, hereafter designated as FSP + aged alloy. The second treated alloy was in as rolled condition and then aged by heating to $720^{\circ} \mathrm{C}$ for 16 hours and air cooled to ambient, hereafter designated as the AR + aged alloy (treated as the baseline condition).

\subsection{Hardness and wear testing}

Microhardness measurements at room temperature were performed using a Shimadzu Vickers hardness tester. Cross-sectional microhardness profile measurements were taken at three different distances from the top surface of the alloy at FSP plunge depths of 2.0, 4.0 and $4.5 \mathrm{~mm}$. An indentation load of 100 grams was used with a 10 seconds loading cycle. A high frequency reciprocating rig (HFRR) from PCS Instruments was used to determine the wear behavior of the $\mathrm{AR}+$ aged and FSP + aged alloys. A 6.35 mm diameter $\mathrm{Si}_{3} \mathrm{~N}_{4}$ ball (Cerbec, NBD200 Grade 5)

with $3 \mathrm{~nm}$ arithmetic surface roughness was used as a sliding counterface. The hard 
$\left(\mathrm{HV}_{0.1}=1975\right) \mathrm{Si}_{3} \mathrm{~N}_{4}$ was selected to mitigate counterface tribochemical phases, e.g., $\mathrm{SiO}_{2}$, from forming in the wear track that could otherwise bias the results. The following HFRR conditions were used in this study: a normal load of $0.2 \mathrm{~N}(=0.35 \mathrm{GPa}$ initial maximum Hertzian contact stress), reciprocating stroke length of $1 \mathrm{~mm}$, reciprocating frequency of $20 \mathrm{~Hz}$ for a duration of 90 min (=216 m total sliding distance). The normal load/contact stress was chosen as to be below the 0.65 GPa yield strength of age hardened A-286 alloy. All experiments were carried out at room temperature and $\sim 50 \%$ relative humidity in lab air. The $1 \mathrm{~mm}$ long wear tracks were generated perpendicular to the FSP welding direction in order to obtain more wear tracks inside the friction stir welded region. For repeatability purposes, at least five HFRR measurements were taken for each treated alloy. After sliding, stylus profilometry (Veeco Dektak 150 Profilometer) was used to measure the cross-sectional wear area removed and wear depth inside each wear track. At least five profilometry traces were taken across the length of each wear surface excluding near the turnaround ends. The wear rate, expressed in $\mathrm{mm}^{3} / \mathrm{N} \cdot \mathrm{m}$, was calculated as the wear surface volume removed divided by the load and the total distance traveled by the counterface ball.

\subsection{Surface and subsurface structural and chemical characterization}

Before and after the wear tests, the surfaces were analyzed by a combination of structural and chemical characterization techniques. The structural phases of the A-286 alloy for both processing conditions were determined by X-ray diffraction (XRD). A Rigaku Ultima III diffractometer was used in normal incidence mode using $\mathrm{CuK} \alpha$ x-rays. In addition, electron back scatter diffraction (EBSD) was performed inside a scanning electron microscope (SEM), FEI-Nano SEM 230, to determine grain size and number fraction and grain orientation for AR +

aged and FSP + aged alloys. EBSD maps were acquired along the transverse cross-section inside 
and outside the friction stir zone. Optical images of the alloy wear tracks and $\mathrm{Si}_{3} \mathrm{~N}_{4}$ ball surfaces were acquired with an Olympus U-TV0 optical microscope. In addition, an FEI-Nova 200 dual beam Scanning Electron Microscope/Focused Ion Beam (SEM/FIB) system was used to image the surface and subsurface of the A-286 alloy wear surfaces. Site selective, cross-sectional FIBSEM studies were acquired on the AR + aged alloy inside and outside the wear track. In addition, FIB-SEM images were taken on the FSP + aged alloy inside the friction stir zone and inside the wear track generated on the friction stir zone. The ion beam was operated at a conservatively low voltage of $5 \mathrm{keV}$ and current of $1.6 \mathrm{nA}$ for during FIB-SEM imaging. Electron e-beam Pt followed by ion i-beam Pt were deposited on the alloy surfaces prior to FIB milling to protect the surfaces from Ga ion implantation and structural damage.

Auger electron spectroscopy (AES) was used to analyze the chemical composition changes inside the wear tracks. The AES analysis was performed with a PHI 670xi scanning Auger nanoprobe working at an energy range between $10-20 \mathrm{keV}$ and a beam current of $\sim 10 \mathrm{nA}$. The electron column in the AES vacuum chamber was used to obtain SEM images with magnifications of up to 20,000X by using raster scanning with a highly focused electron beam. In addition, site-specific micro-Raman spectroscopy measurements were acquired inside the wear tracks using a Thermo Electron Almega XR dispersive Raman spectrometer with $\sim 1 \mu \mathrm{m}$ spot size and $532 \mathrm{~nm}$ excitation wavelength. Raman spectra were obtained at a low power laser density of $\sim 25 \mathrm{~mW} / \mu \mathrm{m}^{2}$; at this power density, no changes in the spectra due to laser surface heating were observed. The acquisition times were $10 \mathrm{~s} /$ spectrum with four total accumulations taken to average each spectrum. Raman shifts were measured over a frequency range from 200 to $1200 \mathrm{~cm}^{-1}$, with $\sim 2 \mathrm{~cm}^{-1}$ resolution. 


\section{Results and discussion}

\subsection{Microstructure}

Fig. 1 shows the XRD scans of the stainless steel A-286 alloy for both AR + aged and FSP + aged conditions. It is evident that the solid solution FCC austenite $(\gamma)$ phase is only present with reflections of (111), (200) and (220) for both AR + aged and FSP + aged alloys. No peak shifts, broadening or significant changes in x-ray intensities were observed for both alloys. Therefore, there were no phase transformations in the alloy microstructures due to ageing and FSP, i.e., the austenitic structure is retained during both treatments. Fig. 2 shows EBSD maps and corresponding grain size number fraction plots of AR + aged and FSP + aged alloys. These transverse cross-sectional maps were acquired outside (Fig. 2a) and inside the center of friction stir zone (Fig. 2c), which represent the AR + aged and FSP + aged conditions, respectively. The EBSD map and corresponding grain size number fraction for AR + aged alloy in Figs. 2(a) and 2(b) show randomly orientated grains mostly with sizes on the order of tens of microns, whereas the grain size as expected is much finer in the friction stir zone, i.e. average grain size of 2-3 $\mu \mathrm{m}$. In addition, from the EBSD map in Fig. 2(c) there appears no evidence of FSP-induced crystallographic texturing of the grains. The effects of this grain refinement in the FSP + aged alloy on microhardness and wear resistance will be discussed below.

\subsection{Microhardness}

Fig. 3 shows the Vickers microhardness cross-sectional profiles of the FSP + aged alloy acquired along the aged retreating side (RS), FSP heat affected zone (HAZ), FSP stir zone (SZ) and aged advancing side (AS). The three curves represent microhardness profiles measured at three different FSP plunge depths of 2, 4, and $4.5 \mathrm{~mm}$ from the top surface of the alloy. Clearly 
inside the SZ there are significant improvements in Vickers microhardness values compared to the HAZ and aged regions. At all three depths, the alloy showed increasing hardness due to FSP. In addition, the results show that the greater the depth, the narrower the SZ (because of the conical pin profile and lower temperature) and the greater the hardness of the alloy that signifies that hardness is dependent on FSP depth. While the baseline hardness of the AR + aged alloy already exhibited precipitation hardening, this further hardness increase due to FSP is attributed to grain refinement shown in Fig. 2(c) (Hall-Petch strengthening) and strain hardening in the SZ, to be discussed in the next section. This improvement in the microhardness is expected to reduce the sliding contact wear area under an applied normal load, and hence decrease the wear rate.

\subsection{Wear behavior}

Table 1 summarizes the HFRR wear data for both the AR + aged and FSP + aged alloys. Based on all of these values, wear is minimized in the alloy due to FSP. The $5.8 \times 10^{-7} \mathrm{~mm}^{3} / \mathrm{N} \cdot \mathrm{m}$ wear rate for the FSP + aged alloy is considered a very low value.

Table 1. Summary of averaged wear track depth, cross-sectional wear area removed, and wear rate with standard deviations for AR + aged and FSP + aged (4.0 mm depth) A-286 alloys.

\begin{tabular}{|l|c|c|c|}
\hline Alloy & $\begin{array}{c}\text { Wear track } \\
\text { depth }(\boldsymbol{\mu m})\end{array}$ & $\begin{array}{c}\text { Wear area } \\
\left(\boldsymbol{\mu m}^{2}\right)\end{array}$ & $\begin{array}{c}\text { Wear rate } \\
\left(\mathbf{m m}^{\mathbf{3}} \mathbf{/ N} \cdot \mathbf{m}\right)\end{array}$ \\
\hline AR + aged & $0.52 \pm 0.13$ & $44 \pm 17$ & $1.0 \pm 0.2 \times 10^{-6}$ \\
\hline FSP + aged & $0.45 \pm 0.12$ & $24 \pm 9$ & $5.8 \pm 0.3 \times 10^{-7}$ \\
\hline
\end{tabular}

This can be attributed in part to the increased microhardness in the SZ due to the reduction in grain size shown by EBSD map in Fig. 2(c) that leads to Hall-Petch strengthening. After sliding, optical microscopy images were acquired to examine the surface wear morphology and debris on the A-286 alloy wear tracks and mating $\mathrm{Si}_{3} \mathrm{~N}_{4}$ sliding counterface balls. Fig. 4 shows the worn images for AR + aged (top row) and FSP + aged (bottom row) alloys. Visually the wear surfaces 
of the FSP + aged alloy exhibit reduced wear damage, e.g., lower wear contact area and much less abrasive wear damage/debris on track and ball, compared to the AR + aged alloy. In addition to optical microscopy, higher magnification SEM imaging was conducted on the respective wear tracks. Clearly the wear track SEM morphologies are different: increased coarse micro-abrasion (galling) with AR + aged alloy in Fig. 4(c) and much finer-scale micro-abrasion with the FSP + aged alloy in Fig. 4(f). As a result, the wear debris is larger for the AR + aged alloy, which confirms the previous observations based on the optical images. These differences are consistent with the FSP + aged alloy exhibiting a shallower wear depth, wear area and lower wear rate compared to the AR + aged alloy. However, the mechanism behind such wear behavior needs further investigation and will be discussed now.

\subsection{Wear mechanisms}

Cross-sectional FIB-SEM was used in order to observe microstructural differences responsible for the wear results. Such microscopy studies of the cross-sections inside and outside the wear tracks were acquired after HFRR testing to determine the microstructural evolution during wear for both AR + aged and FSP + aged alloys. Figs. 5(a) and 5(b) show FIBSEM cross-sectional images prior to wear for (a) AR + aged alloy and (b) FSP + aged alloy inside the SZ, respectively. This comparison shows that there is FSP-induced microscopic grain refinement in the FSP SZ, in accordance with EBSD map in Fig. 2(c), with increasing subsurface grain boundaries, shown in Fig. 5(b). This grain refinement is responsible for the increase in hardness in the SZ (Fig. 3) via Hall-Petch strengthening as well as the subsequent reduction of wear rate and micro-abrasion in the wear track shown in Fig. 4(f). In contrast, there is lower hardness and higher wear rate with the absence of FSP-induced microscopic grain refinement in 
the AR + aged alloy, shown in Fig. 5(a). Without enhanced hardness, there is increasing microabrasion, shown by the surface wear track morphology in Fig. 4(c). Therefore, FSP-induced grain refinement reduces the level of micro-abrasion, shown in Fig. 4(f), and limits surface fatigue wear. Lastly, there is an FSP tool shoulder-induced flow layer in the near surface ( 100 nm deep) of FSP + aged alloy in Fig. 5(b), which is common during FSP due to the geometry of the tool.

Figs. 6(a) and 6(b) show representative low and higher magnification cross-sectional FIB-SEM images, respectively, of the AR + aged alloy inside the wear track after HFRR testing. In comparison to the unworn AR + aged alloy cross-section shown in Fig. 5(a), there exists a wear-induced subsurface zone consisting of likely strain hardened material (darker due to imaging channeling contrast) along with nanoscopic refined grains. However, these and other images not shown display a minimal amount of wear-induced grain refinement that translates to lower hardness and higher wear rates. Specifically, the AR + aged alloy exhibits lower hardness (Fig. 3), since there was no FSP-induced grain refinement, along with increased abrasive wear (Figs. 4(a)-4(c)) due to a minimal amount of wear-induced grain refinement.

Figs. 7(a) and 7(b) show representative low and higher magnification cross-sectional FIB-SEM images, respectively, of the FSP + aged alloy inside the wear track after HFRR testing. In comparison to the unworn FSP + aged alloy cross-section shown in Fig. 5(b), there exists several sliding wear-induced subsurface zones consisting of strain hardened material (darker channeling contrast) and a near surface layer comprised of nanoscopic refined grains. This latter zone is more continuous and deeper than the one generated during wear of the AR + aged alloy shown in Fig. 6(b), which could further lead to increased hardness in the wear track. When 
coupled with the enhanced hardness due to FSP, there is a reduction in the extent of abrasion as evident by comparing the wear track surface images of the alloys in Figs. 4(e) and 4(f) versus Figs. 4(b) and 4(c). The nanoscopic and microscopic grain refinement resulting from wear in Fig. 7 and FSP in Fig. 5(b), respectively, reduced the level of micro-abrasion and surface fatigue wear. This accounts for the lowering of the wear depth, area and rate of the FSP + aged alloy. In addition, subsurface wear-induced shear/slip deformation bands and strain hardening shown in Fig. 7(a) and Fig. 7(b), respectively, could also contribute to improved wear resistance.

The darker features shown by the ion beam channeling contrast images in Figs. 4 and 5 for both alloys are a result of deformation from work hardening during sliding rather than the formation of a new phase or chemical compound, which could form by stress-assisted or tribochemical reaction, respectively. This was substantiated by XRD and energy dispersive spectroscopy (EDS) in the SEM that did not detect any new structural phases or chemical compounds, respectively. However, XRD and EDS have difficulty in detecting near surface structural phases and chemical compositions. Therefore, scanning Auger electron spectroscopy (AES) and Raman spectroscopy were used to determine if such phases and compounds exist on the near surfaces of the FSP + aged alloy. Fig. 8 shows AES profiles acquired from two regions inside the wear track. The area labeled one inside the wear track in Fig. 8(a) contained silicon and oxygen peaks shown in Fig. 8(b), which likely coexist as an amorphous $\mathrm{SiO}_{2}$ phase based on a previous study with the same counterface and HFRR testing [12]. This wear debris transferred from the worn sliding $\mathrm{Si}_{3} \mathrm{~N}_{4}$ counterface shown in Fig. 4(d). In contrast, the area labeled two inside the wear track showed a different chemical spectrum in Fig. 8(b) consisting of the main A286 alloying elements $\mathrm{Fe}, \mathrm{Ni}$ and $\mathrm{Cr}$ with a very small amount of oxygen. Therefore, there is also likely some alloy metal oxide wear debris on the surface. However, this wear debris is non- 
continuous since the FIB-SEM images in Fig. 7 did not detect any surface films albeit the films may be too thin to detect with SEM. These silicon oxide and metal oxide wear debris make up a small portion of the wear track contact area, and thus are a consequence and not the cause of low wear rates. To confirm if metal oxide phases are present, micro-Raman spectroscopy measurements were acquired on the wear track surface. Fig. 9 shows two micro-Raman spectra acquired at different locations inside the wear track. While there are weak intensity counts, indicative of a very thin layer, it is evident that the wear debris contains metal oxide phases of $\mathrm{Fe}_{3} \mathrm{O}_{4}, \mathrm{Cr}_{2} \mathrm{O}_{3}$, and $\mathrm{NiO}$. The broad micro-Raman peaks indicate that these metal oxides exhibit an amorphous structure. Lastly, the above spectroscopy techniques did not detect any transfer films or third bodies adhered to the counterfaces (Fig. 4). Therefore, the wear-induced structures of the alloys shown in the FIB-SEM images control the wear behavior and deformation mechanisms.

Previous studies also confirm that FSP results in surface hardening and lowering of wear rates of steels (AISI 1080 [3], 420 [6], and 4140 [10]) compared to conventionally hardened steel control samples. In general, these studies concluded that such improvement in mechanical and wear behavior was a result of both microscopic grain refinement and deformation-induced martensitic phase transformation. In the case of 1080 carbon steel [3], FSP resulted in a pearlite to martensite transformation responsible for increased hardness and wear resistance. During FSP of 420 martensitic stainless steel [6], finer, harder martensite grain size was achieved during FSP with retained austenite detected in some regions resulting in overall improved hardness and wear resistance. For FSP of 4140 low carbon steel [10], FSP-induced grain refinement of the austenite phase produced ultra-fine grained martensite upon phase transformation. While FSP microscopic grain refinement has been observed in the present study, a deformation-induced 
martensitic transformation was not unequivocally proven, but it may have occurred if proper martensitic etchant was used to show the martensite phase. However, the aforementioned studies did not show cross-sectional subsurface structural evolution inside the wear tracks detailing the complex wear zones responsible for lowering of the wear rate with FSP.

\section{Summary and Conclusions}

This study investigated the effect of friction stir processing on the wear behavior of A286 stainless steel alloy. Friction stir processing was used as a surface engineering technique for microstructural modification of this alloy with the aim to increase hardness and decrease wear rate. In addition to measuring mechanical and wear properties, novel fundamental mechanisms responsible for such behavior were determined using FIB-SEM, XRD, EBSD, AES, and Raman spectroscopy inside stir zones and wear tracks. Based on the experimental results and characterization analyses, the following conclusions were determined for A-286 alloys processed in different conditions of AR + aged and FSP + aged:

- The FSP + aged alloy exhibited the lowest wear rate of $5.8 \times 10^{-7} \mathrm{~mm}^{3} / \mathrm{N} \cdot \mathrm{m}$ compared to the AR + aged alloy wear rate of $1.0 \times 10^{-6} \mathrm{~mm}^{3} / \mathrm{N} \cdot \mathrm{m}$.

- In part, the increasing microhardness in the stir zone due to FSP-induced microscopic grain refinement was responsible for decreasing wear rates. In contrast, the absence of FSP-induced grain refinement in the AR + aged alloy resulted in lower hardness, and hence increasing wear rate.

- Further improvement in the wear resistance of A-286 alloy was due to wear-induced nanostructural grain refinement/Hall-Petch strengthening. 
- There was increased coarse micro-abrasion with the AR + aged alloy compared to the much finer-scale micro-abrasion with the FSP + aged alloy, which was responsible for smaller and less abrasive wear debris, and hence lower wear rate.

- Micro-Raman spectroscopy inside the stir wear zone determined that the wear debris contained metal oxides of $\mathrm{Fe}_{3} \mathrm{O}_{4}, \mathrm{Cr}_{2} \mathrm{O}_{3}$, and NiO. Scanning Auger spectroscopy revealed that some areas of the wear track also contained silicon oxide wear debris transferred from the worn sliding $\mathrm{Si}_{3} \mathrm{~N}_{4}$ counterface. However, this wear debris makes up a small portion of the wear track contact area, and thus is a consequence and not the cause of low wear rates.

Overall, friction stir processing of A-286 stainless steel alloy resulted in lowering of the wear rate suggesting it is a viable surface engineering technique to mitigate and target site-specific wear.

\section{Acknowledgements}

This work was supported under the NSF-IUCRC grant for Friction Stir Processing. The additional support of NSF-IIP (1157754) and Rolls-Royce Corporation for the UNT site is acknowledged. This report was prepared as an account of work sponsored by an agency of the US Government. The views and opinions of the authors expressed herein do not necessarily state or reflect those of the US Government or any agency thereof. We also acknowledge the UNT Center for Advanced Research and Technology (CART).

\section{References}


[1] R.S. Mishra, Z.Y. Ma, Friction stir welding and processing, Mater. Sci. Eng. R 50 (2005) 178.

[2] R.S. Mishra, P. Sarathi De, N. Kumar, Friction stir welding and processing, Science and Engineering, Springer, New York, New York, 2014.

[3] S.H. Aldajah, O.O. Ajayi, G.R. Fenske, S. David, Effect of friction stir processing on the tribological performance of high carbon steel, Wear 267 (2009) 350-355.

[4] N. Sun and D. Apelian, Friction stir processing of aluminum cast alloys for high performance applications, JOM (2011) 44-50.

[5] H.S. Arora, H. Singh, B.K. Dhindaw, Wear behavior of a Mg alloy subjected to friction stir processing, Wear 303 (2013) 65-77.

[6] S. Dodds, A.H. Jones, S. Cater, Tribological enhancement of AISI 420 martensitic stainless steel through friction-stir processing, Wear 302 (2013) 863-877.

[7] R. Li, T. Yuan, Z. Qiu, K. Zhou, J. Li, Nanostructured Co-Cr-Fe alloy surface layer fabricated by combination of laser clad and friction stir processing, Surf. Coat. Technol. 258 (2014) 415-425.

[8] B. Li, Y. Shen, W. Hu, and L. Luo, Surface modification of Ti-6Al-4V alloy via friction-stir processing: Microstructure evolution and dry sliding wear performance, Surf. Coat. Technol. 239 (2014) 160-170.

[9] A. Rahbar-kelishami, A. Abdollah-zadeh, M.M. Hadavi, R.A. Seraj, A.P. Gerlich, Improvement of wear resistance of sprayed layer on 52100 steel by friction stir processing, Appl. Surf. Sci. 316 (2014) 501-507.

[10] C. Lorenzo-Martin, O.O. Ajayi, Rapid surface hardening and enhanced tribological performance of 4140 steel by friction stir processing, Wear 332-333 (2015) 962-970. 
[11] M. Esfandiari, H. Dong, Improving the surface properties of A286 precipitation-hardening stainless steel by low-temperature plasma nitriding, Surf. Coat. Technol. 201 (2007) 6189-6196.

[12] V. Ageh, D. Choudhuri, and T.W. Scharf, High frequency reciprocating sliding wear behavior and mechanisms of quaternary metal oxide coatings, Wear 330-331 (2015) 390-399.

\section{Figure Captions}

Fig. 1. XRD scans of AR + aged and FSP + aged A-286 alloys.

Fig. 2. Cross-sectional EBSD maps and corresponding grain size number fractions of (a,b) AR + aged and (c,d) FSP + aged A-286 alloys. The color associated with each grain represents a particular crystallographic axis perpendicular to the plane of the paper, and its index can be assessed from the inverse pole figure triangle in inset of (a) and (c).

Fig. 3. Vickers microhardness cross-sectional profiles acquired at three different plunge depths from top surface of FSP + aged A-286 alloy. SZ=Stir zone, HAZ=Heat affected zone, RS=Retreating side, and AS=Advancing side.

Fig. 4. Optical microscopy images of (a) $\mathrm{Si}_{3} \mathrm{~N}_{4}$ ball sliding on (b) $\mathrm{AR}+$ aged wear track, and (c) higher magnification SEM image of wear track in (b). Optical microscopy images of (d) $\mathrm{Si}_{3} \mathrm{~N}_{4}$ ball sliding on (e) FSP + aged wear track, and (f) higher magnification SEM image of wear track in (e).

Fig. 5. Cross-sectional FIB-SEM images of (a) AR + aged A-286 alloy and (b) FSP + aged alloy acquired in the SZ before wear. The thicker arrows in (b) show a near surface FSP tool shoulder induced flow layer.

Fig. 6. Cross-sectional FIB-SEM (a) low and (b) high magnification images of AR + aged A286 alloy acquired inside the wear track.

Fig. 7. Cross-sectional FIB-SEM (a) low and (b) high magnification images of FSP + aged A286 alloy acquired inside the wear track.

Fig. 8. Scanning Auger (a) secondary electron image and (b) corresponding spectroscopy scans (Areas 1 and 2) acquired inside wear track on SZ of FSP + aged alloy.

Fig. 9. Micro-Raman spectra acquired inside wear track on SZ of FSP + aged alloy. 


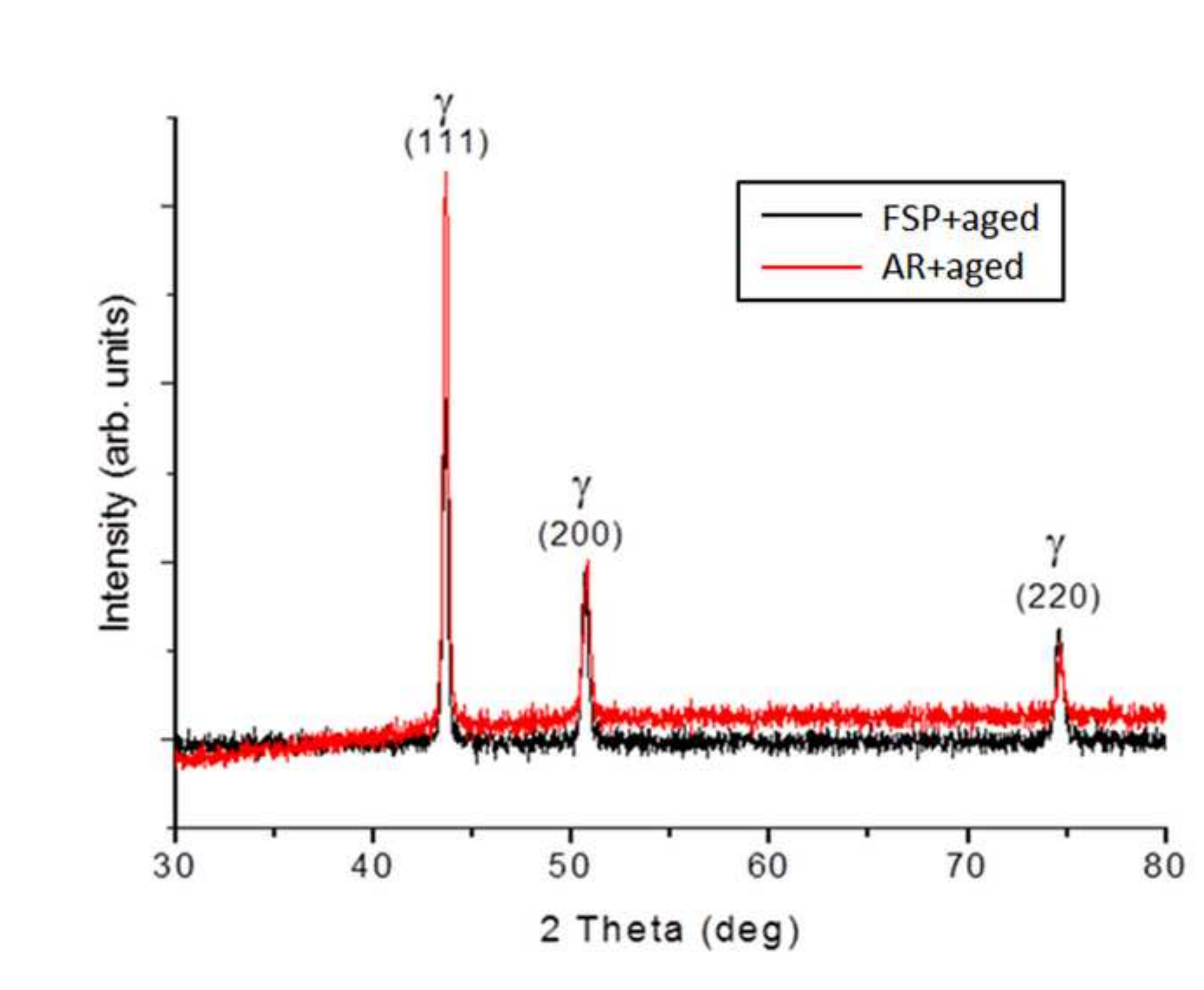

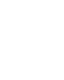

.

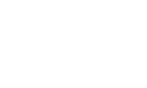

.

.
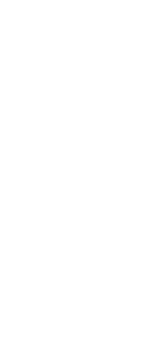

.



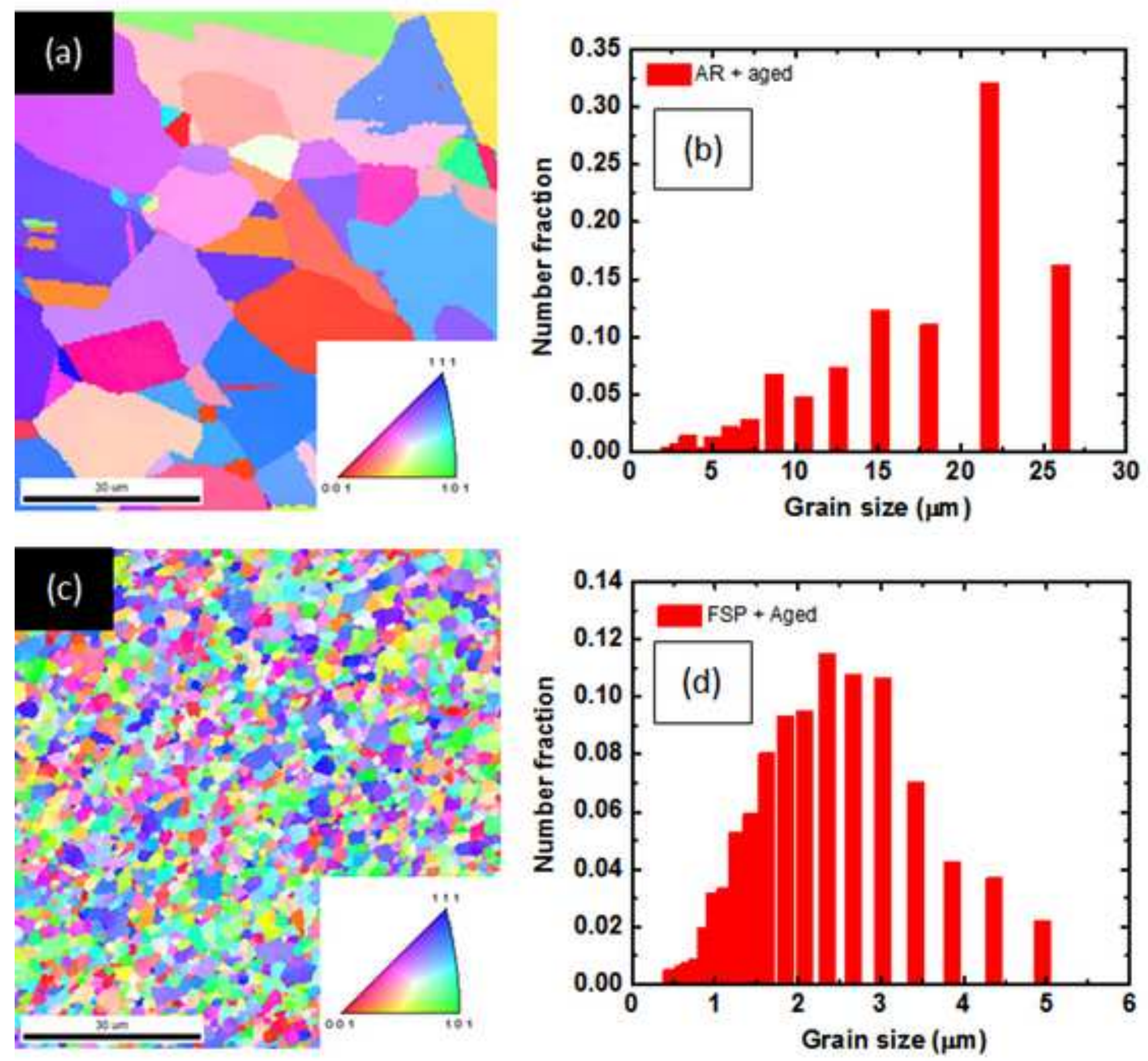


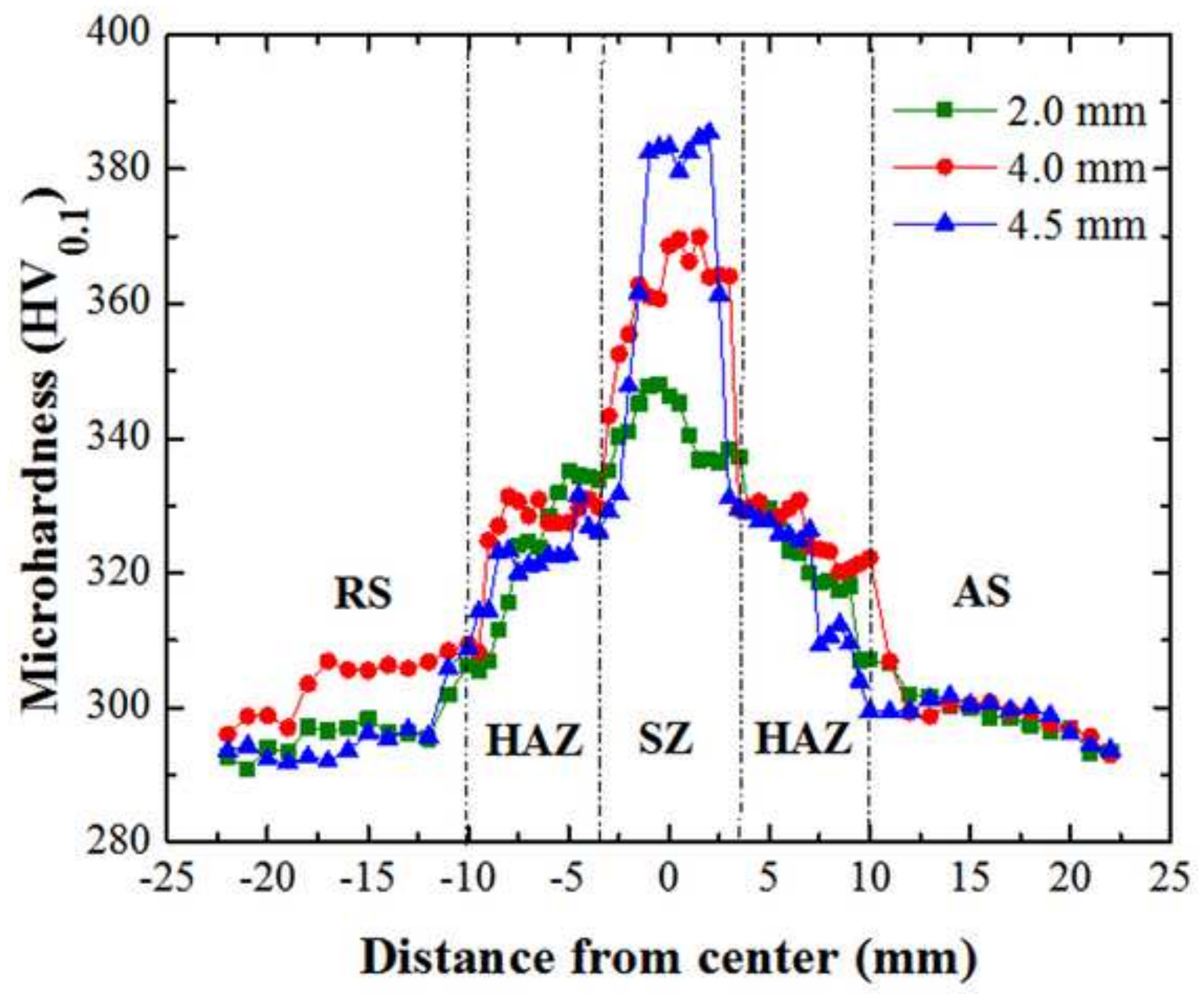



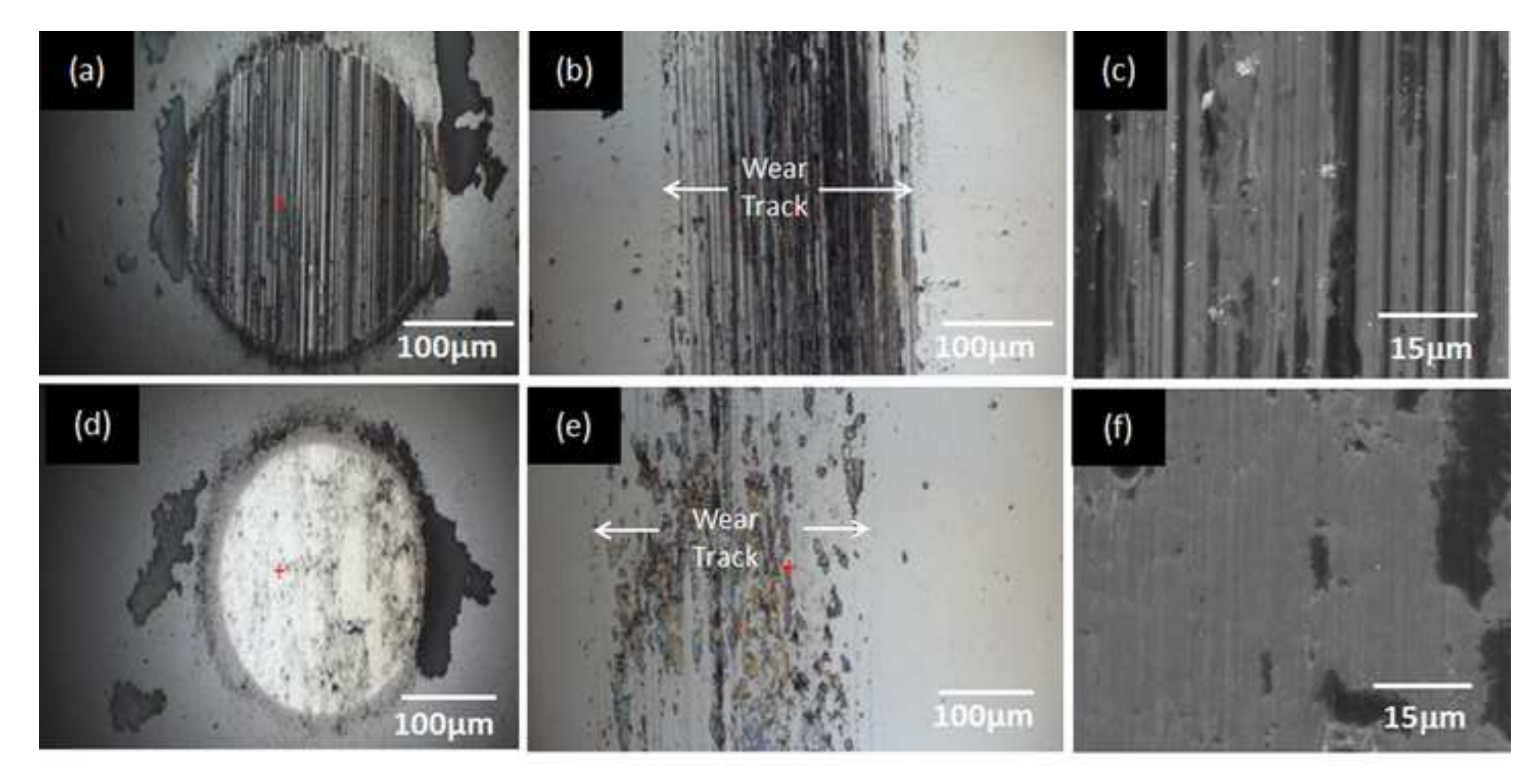

(e)
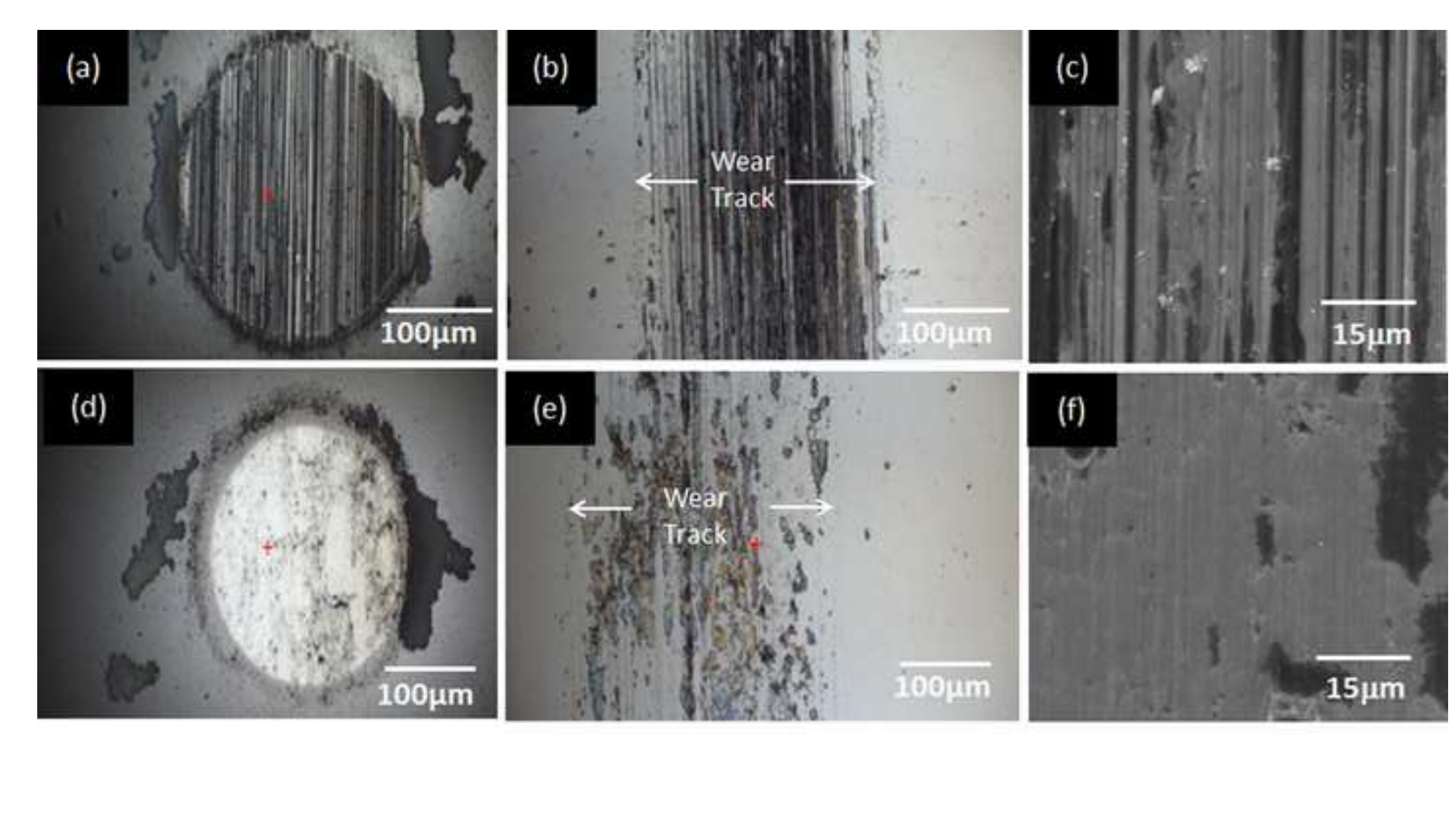

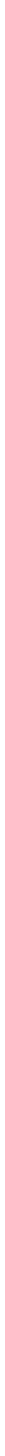

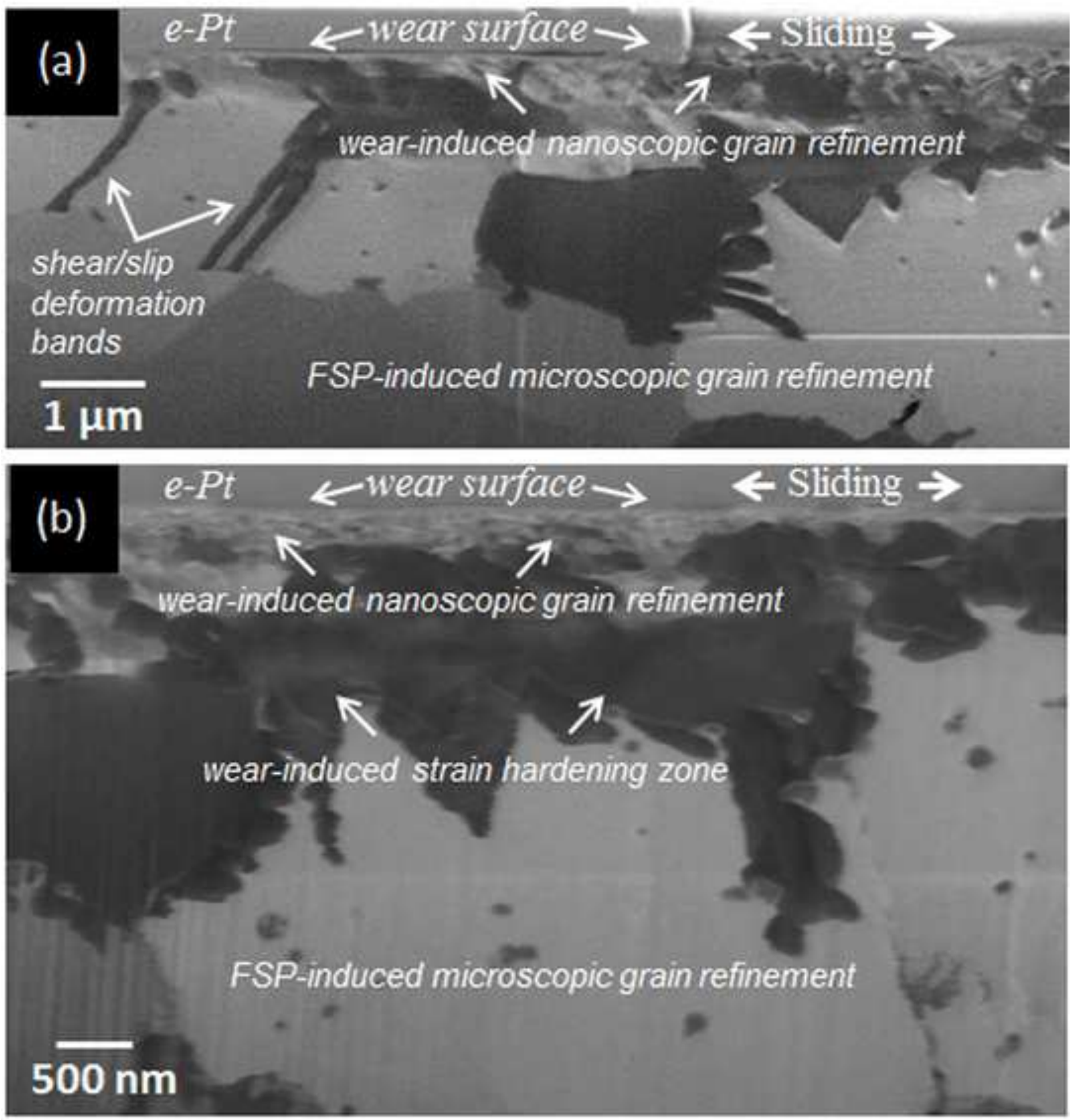

shearksip deformation bands $1 \mu \mathrm{m}$ FSP-induced microscopic grain refinement

\section{(b)}

wear-induced nanoscopic grain refinement

FSP-induced microscopic grain refinement

wear-induced strain hardening zone 


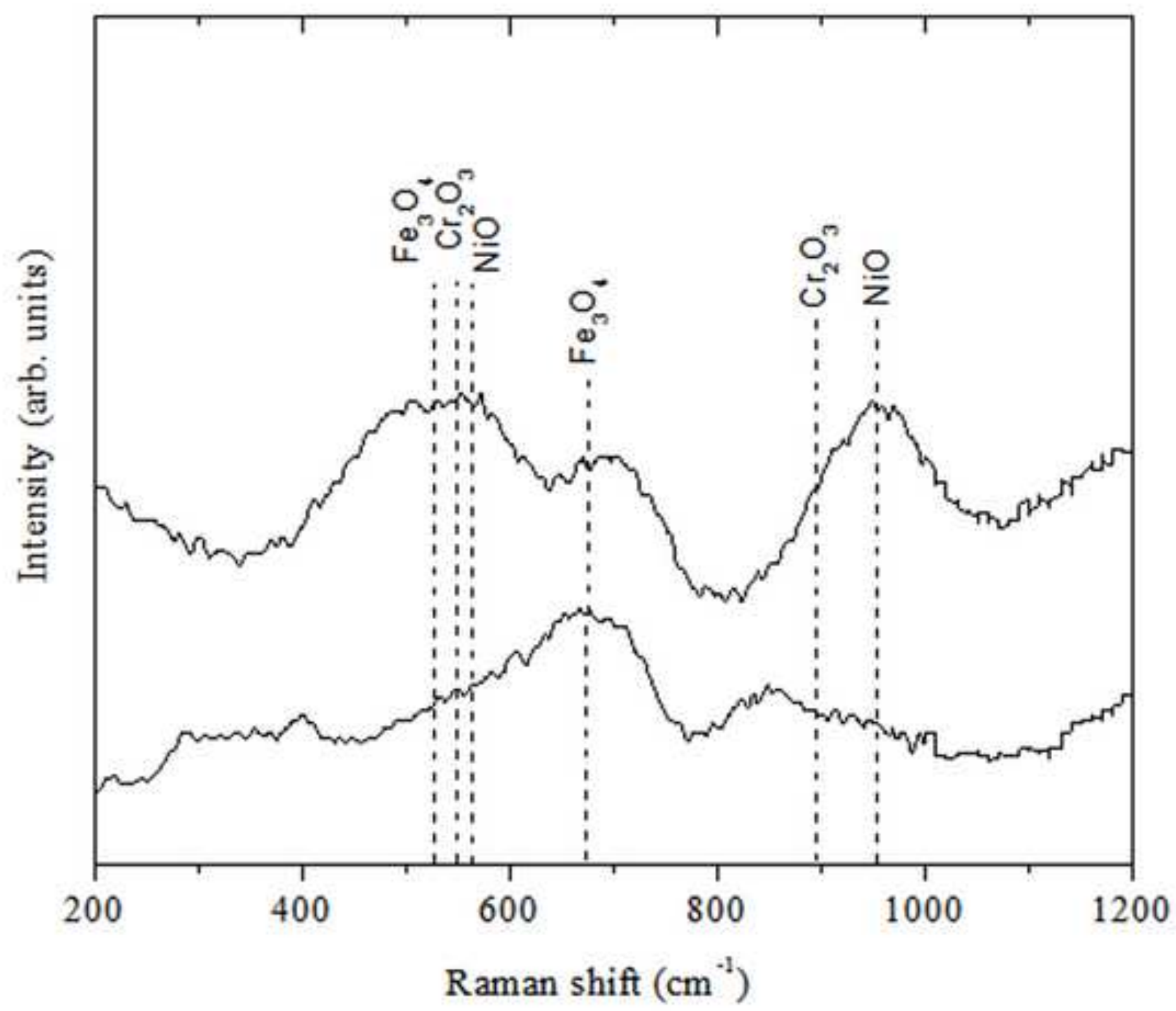

